\title{
Ingenious Agriculture Monitoring System Using IoT And Blynk
}

\author{
Debnath Bhattacharyya $^{1}$, N. Thirupathi Rao², K. Swathi 3* \\ 1,2 Department of Computer Science and Engineering, Vignan's Institute of \\ Information Technology, Visakhapatnam, AP, India \\ ${ }^{3}$ Corresponding author, Associate Professor, Major in Real Estate Studies, Faculty of \\ Regional Development, Kongju Nat'l University. Yesan, Chungnam, South Korea \\ ${ }^{1}$ nakkathiru@gmail.com,2debnathb@gmail.com, ${ }^{3}$ limsejung@korea.ac.kr
}

\begin{abstract}
Changes in atmosphere over the last decades had become tremendous changes in the agriculture and the rainfall. Most of the agricultural works are dependent on rain and rainfall, the supply of water to the fields and agricultural lands is more important. Farmers are suffering a lot with the short of rainfall and other issues and the water is the most important aspect or the consideration for the growth of any agriculture related plants or the seeds. Internet of Things plays a key role in helping the farmers by observing the right time and situation for the plants to farm and also for the water to supply the plants at various intervals of time. With IoT, various types of sensors can be used to identify the actual water levels and other temperatures and other parameters to be noted time to time and the immediate actions can be taken. In order to improve the output from these fields, monitoring and providing the required suppliants at right time is more important. In the current work, an IoT based Android and Blynk based application had developed to monitor such parameters and try to provide the required supplements at right time for the better growth of the plants and other types of agricultural fields. By using the current application, the farmers can get the data regarding soil moisture, water level at the roots of the plants, pest control levels to be maintained, humidity on day wise and temperature at various intervals of time. These are some of the important factors to be considered for the better output or better growth of any plants in agriculture. By using this method, the farmers can directly get the data to their mobile phones as the unit was directly connected with the mobile phones of the farmers and they can take the immediate actions based on the data that they are receiving time to time.
\end{abstract}

Keywords: Agriculture, Sensors, Blynk, Arduino, temperature, WiFi, Mobile Phones, Humidity, Water Levels, Pest Control, Nodemcu.

\section{Introduction}

In the recent days of the world, water has become the major constraint for the public to utilize and also to proper utilization for drinking purpose and for the agricultural purposes. The utilization of water to the industries is also an important consideration in the recent days. The amount of water that can be used of drinking and for the use of agriculture was reducing day by day. Hence, there is a need of proper utilization of water at various situations[1][2]. Whenever there is a need of supply of water to plants, then only we need to supply it, in other

Article history:

Received (April 4, 2019), Review Result (June 1, 2019), Accepted (September 13, 2019) 
cases the water can be used for some other plants. Over watering to the plants is also not a good idea of supplying. The main aim of the current work is to supply the water to the plants when there is a requirement by observing the requirement data from the roots of each plant. A sensor is placed to check the water levels at the agriculture land and it always measures the amount of water levels and the data is being supplied to the controlling unit and the farmer through his mobile. The total processing the system can be controlled by the utilization of the unit called ESP8266 Nodemcu unit[3][4][5]. The water flow can be controlled by this unit only.

By using the current system, the watering of the agricultural field or the garden can be automatically given water without the intervention of the human being. The sensors will be placed in different places in the field and the sensors will collect the data periodically and submit the same data to the user and the controlling unit [6][7][8]. The estimated humidity and the other temperature values also implemented and tested with the current unit. The user can use the system by turning on and off and also the machine can also do the same operations based on the data from the sensors. Some of the tasks performed by using the current system are,

Supplying of water to the plants based on the requirement

Transmission of the data to the user

Displaying of the collected data to the user

\subsection{INTERNET OF THINGS}

Internet of Things is the latest technology that was growing rapidly in the recent days. The major beauty of this technology is that with the help of this technology different types of devices with various models can be connected with each other like mobile phones, wireless devices, physical devices, GPS devices and other devices [9][10][11]. Some other devices or the sensors like the temperature sensors, humidity sensors, software sensors, actuators, network sensors etc [20][21]. The major applications of these sensors based units are that they can collect the data from various sensors placed in various locations at which the actual human beings cannot go there and can collect the data [12][13]. The other advantage is that the cost of these sensors is nominal for which the normal people also can afford to develop some sensor based networks or units that can be controlled by the help of these sensors for various applications.

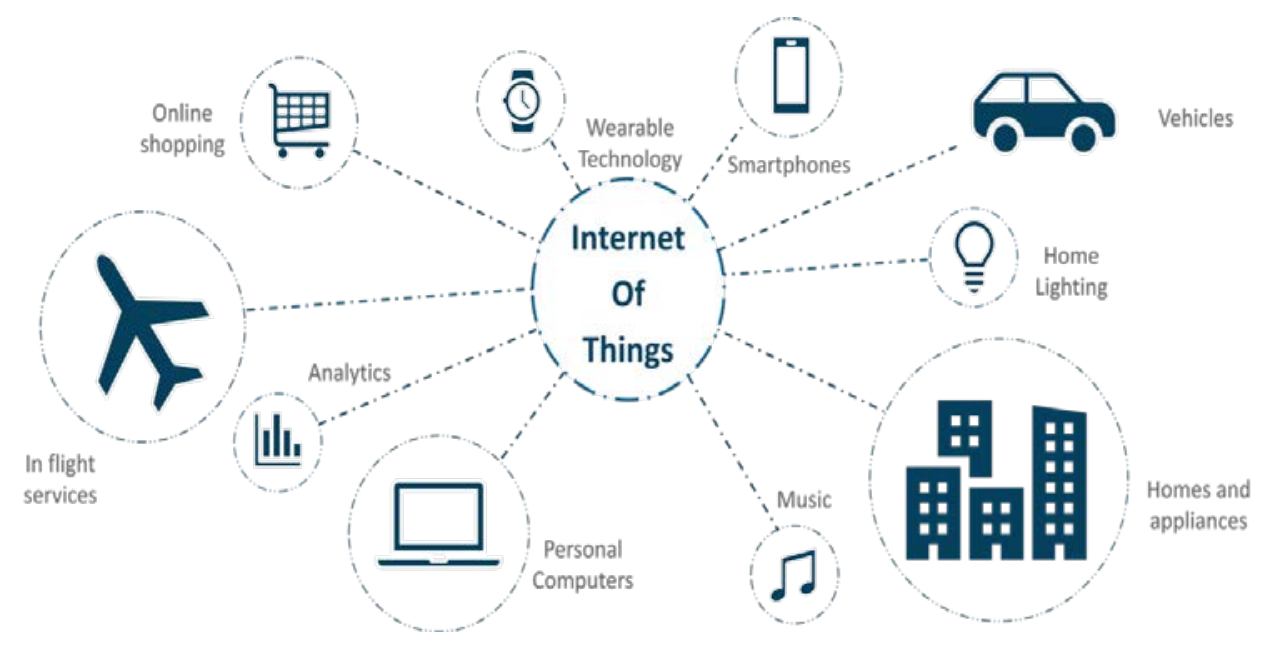

Figure 1. IoT model [1] 
The day to day increase of various technologies and techniques in these models will reduce the intervention human beings and the more productivity will be thee from these devices and less human intervention which will reduce the risk of human life and also the reduced cost of operations [14][15][16]. It is always costly if the intervention of human beings is present and labour charges to be paid for the human beings to work on those points. The utilization of mixing both the sensors and the IoT units with both cyber systems and physical systems which will provide the entire new set of techniques and other models called the Smart Cities and Smart Devices and other Smart Grids etc. Several embedding system models with various depending components also being developed such that to work for more devices with more applications.

\subsection{AGRICULTURE SYSTEMS USING IOT}

Several applications and various devices had been developed so far for the utilization of smart devices to agriculture and its related areas[17][18]. Some of them are Drones for agriculture, greenhouse farming, farming with precisely. They are as follows,

\section{DRONES FOR AGRICULTURE}

Now a days the utilization of advanced technologies for the development of the agriculture [19]. These drones are used for various purposes of works like the collecting the situation of the fields, temperature at various fields, spreading the pesticides and spraying of water etc. Planting of trees and carrying of various objects and related items to the paddy fields are also made easy by these drones.

\section{SMART GREENHOUSES}

Greenhouse farming is getting the good support and more utilization and utility in these days [20]. By using this farming model, the growing of vegetables, fruits, crops and other fruits growing options also growing day by day. The manual intervention sometimes may lead to the losses due to the control mechanism.

\subsection{SENSORS USED IN CURRENT SYSTEM}

Several sensors used in the current proposed model are discussed in detail in the current section. They are as follows,

\section{SOIL MOISTURE SENSOR}

Several sensors are used for identifying and working with the sensors and also to monitor the situation of the various parameters at various situations[14][15][16] These sensors can be used for calculating or identifying the soil moisture, water shortage at various locations, and the level of water at various levels. The water can be either at high level or at low level. The model of the sensor unit was given in detail in the below figure as follows, 


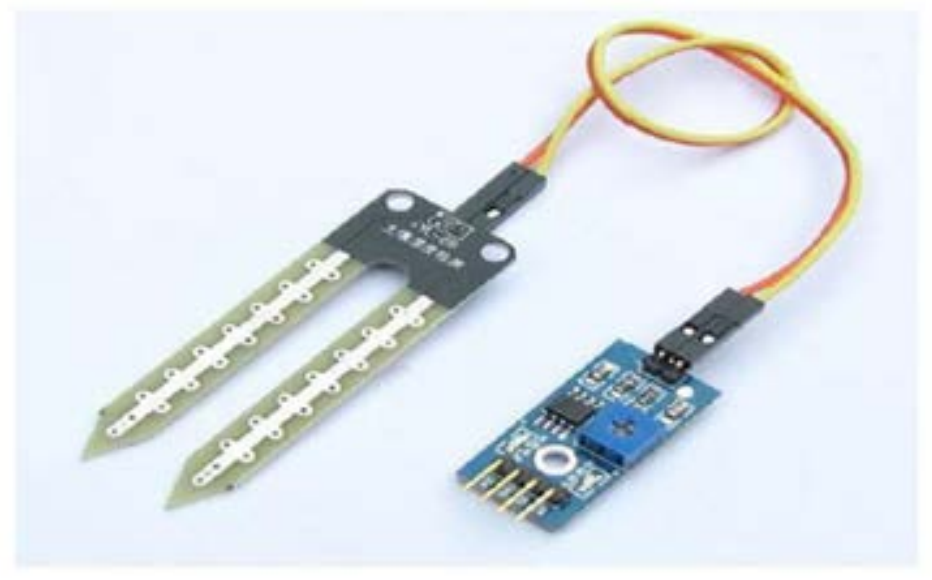

Figure 2. Soil Moisture Sensor

\section{NODE MCU}

The ESP8266 is one of the important devices based on microcontroller which was specifically designed for microcontroller based units [7]. The current unit is a Wi-Fi network based unit and it can be controlled by any mobile device from various locations. The current unit is connected with an USB feature and other setoff pins for various connections [3][4][5]. The unit can be seen as follows,

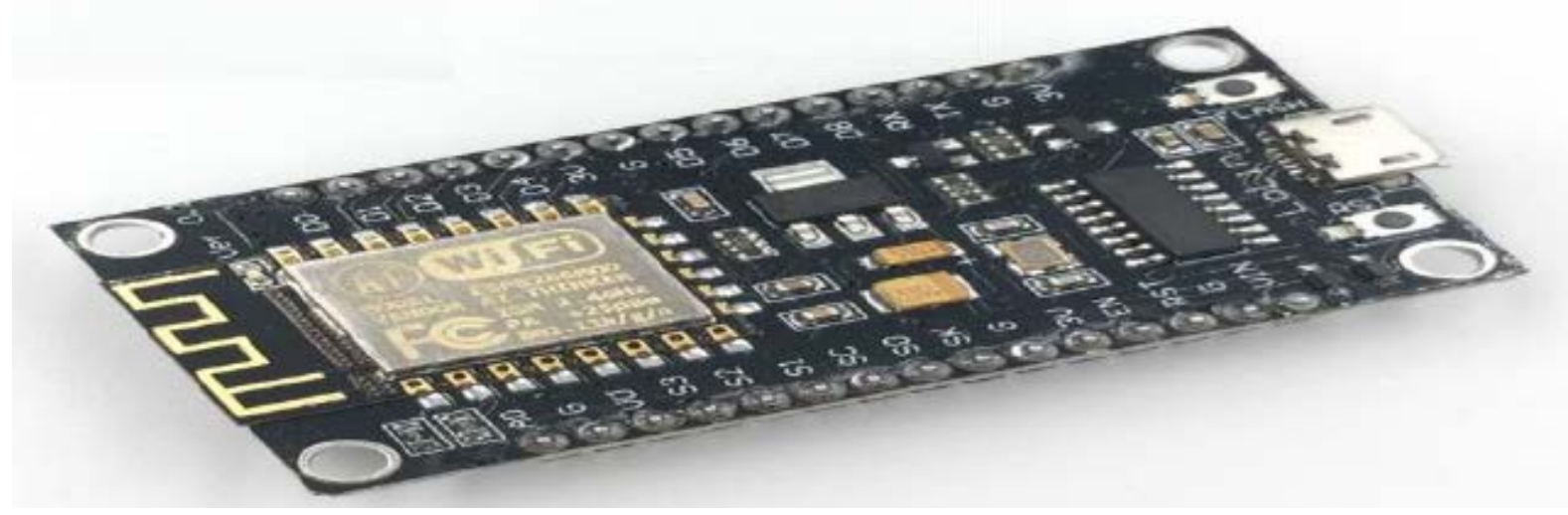

Figure 3. Unit model of Node MCU

The pin description of the current model was also given as follows in the table 1 .

Table 1. Pin Description of ESP8266

\begin{tabular}{|c|c|}
\hline ESP8266 pin & Description \\
\hline CH_PD & Pull high,connect to Vcc +3,3V \\
\hline Vcc & Power Supply $+3.3 \mathrm{v}$ \\
\hline TXD & $\begin{array}{c}\text { Connect to RXD of PL2303HX USB-Serial } \\
\text { converter cable }\end{array}$ \\
\hline
\end{tabular}




\begin{tabular}{|c|c|}
\hline RXD & $\begin{array}{c}\text { Connect to TXD of PL2303HX USB-Serial } \\
\text { converter cable }\end{array}$ \\
\hline GPIO0 & Pull low,connect to GND pin \\
\hline GND & Power Supply ground \\
\hline
\end{tabular}

\section{Motor}

The motor was currently used for water pumping and nonpumping which can be controlled using On/Off options [5][6][7]. The total working of the current machine can be done automatically based on the instructions given from the controlling units. The motor is a DC source motor.

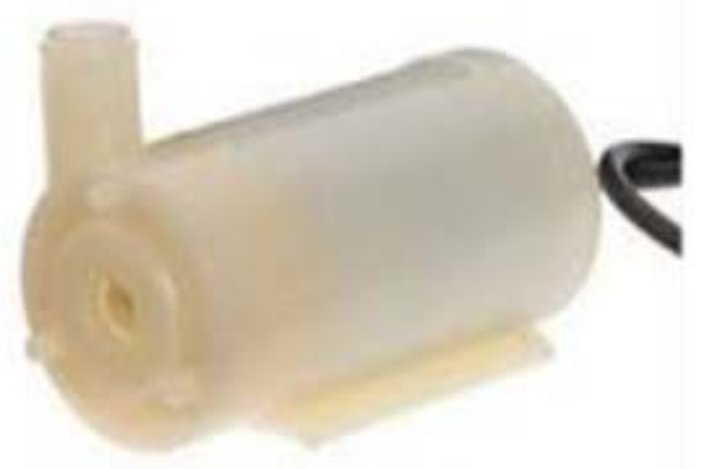

Figure 4. Unit model of DC Motor

The model of the current DC motor can be observed in DC motor.

\subsection{EMBEDDED C}

The current language is an extension of the $\mathrm{C}$ language. The basic $\mathrm{C}$ programming language was extended further for the next level of the language.

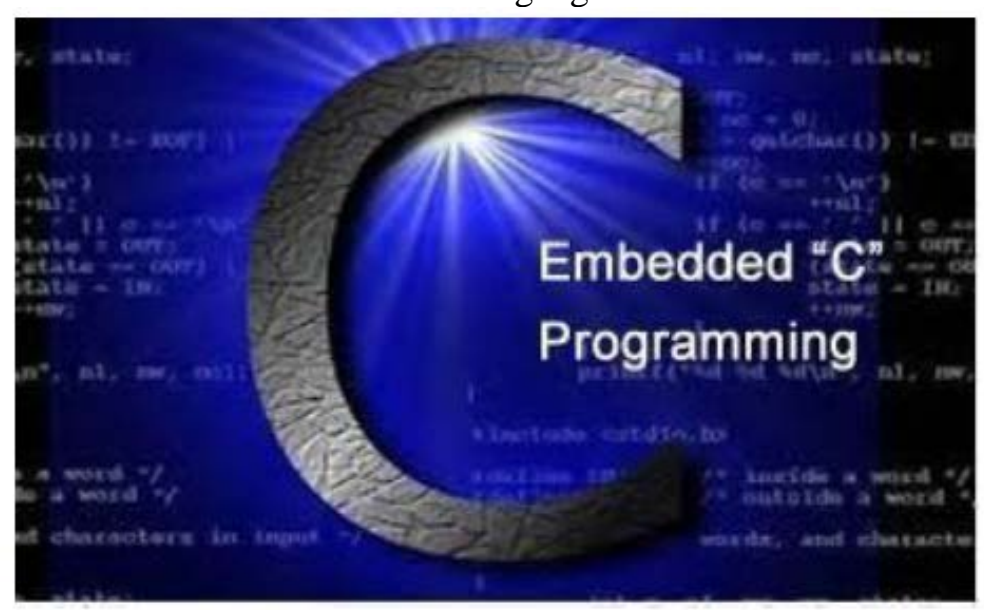

Figure 5. Model of Embedded C Programming

\subsection{Blynk}


The Blynk is an advanced platform that can be used for controlling the Raspberry Pi and Arduino with the help of Internet for the combination of platforms like the IOS Applications and Android. This platform provides us to create an attractive and easy to operate user interface that can be sued for several other applications and gadgets.

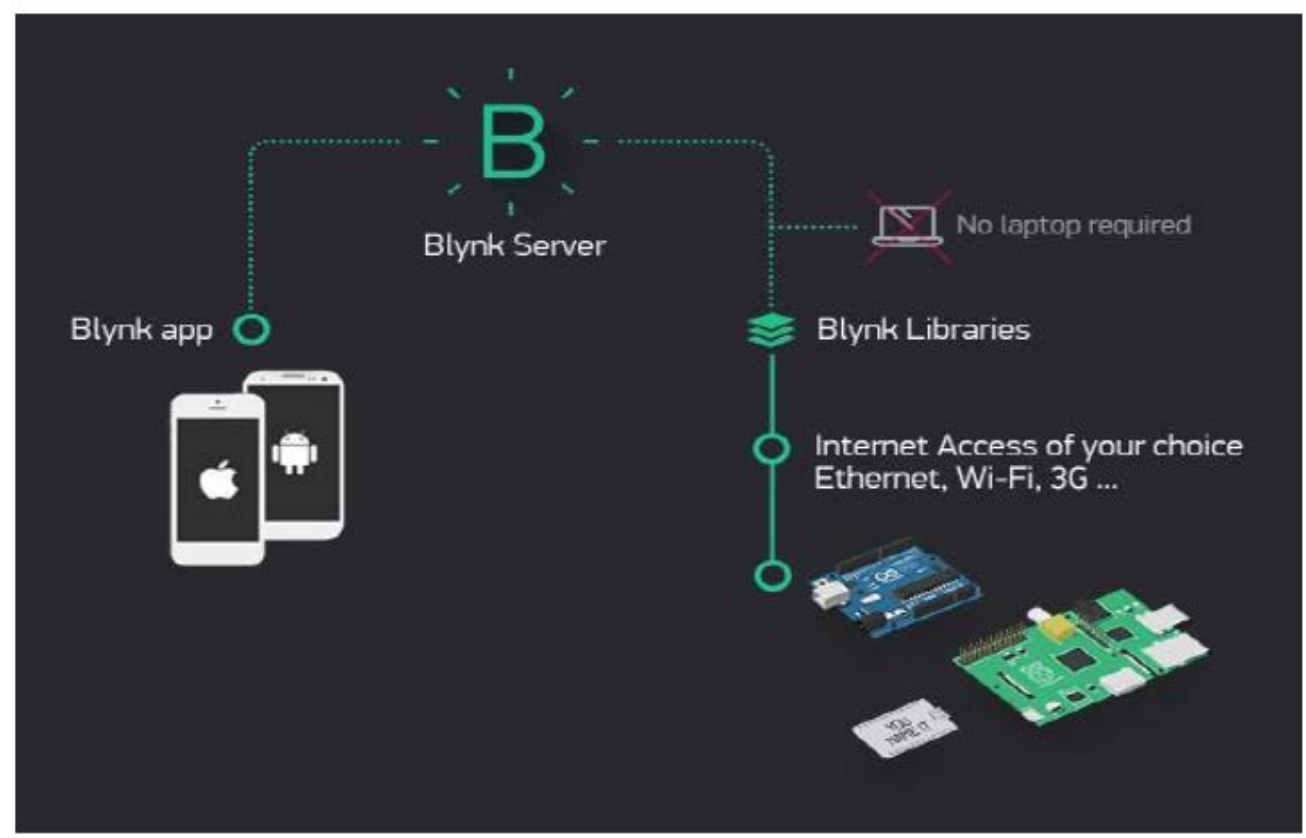

Figure 6. Model of Blynk

\section{LITERATURE REVIEW}

Several authors had done several works for the benefit of the agriculture and for other benefits to the farmers. Some of those works are as follows,

Muthunoori Naresh, P Munaswamy[7] had developed an android based agriculture suggestion system for helping the farmers. The authors had discussed and verified the details regarding the temperature and soil moisture at various places and supply the required materials to those particular places. They had used the IoT unit for the application was ARM processor.

Mohamed Rafiq, Gokul, Pradeep, Vishnu [8] had developed and discussed about the IoT based irrigation system that can help the farmers by various types of suggestions for temperature, humidity, soil type, soil moisture and temperature levels at various points of time etc. They had used various sensors for collecting the data from various places at different intervals of time.

Mrs.T.Vineela, J. NagaHarini, Ch.Kiranmai, G.Harshitha, B.AdiLakshmi[9] had developed the irrigation system based on IoT such that to control the devices by using the Raspberry Pi unit. Several examples and various works were done based on the current model and results are displayed in the results sections. The results are encouraging for the current results point of time for contacting the users with solid amount of data from regular time intervals.

From the above various articles published in recent months, the irrigation system and the study of various factors related to the crops and water levels at various places and the soil types and their details were studied and the authors had used various models. In almost all the cases, the users had not used the development of this IoT system for water management using the 
Blynk software combination with Android such that to work for the better results. The flow control of water also not done with separate DC motors in various existing works so far.

\section{PROPOSED SYSTEM}

In the current work model, an IOT based model had developed for the automatic watering of plants using nodeMCU which is connected to soil moisture sensor and humidity and temperature sensors which will collect the data from the roots of the plants and sends the moisture value and then accordingly the motor pumps the water to the plant. We can also see the value readings from the sensors in the mobile phone with internet connection which displays the moisture content in the soil so that the user can operate the motor ON/OFF.

\section{MODEL DEVELOPEMNT, IMPLEMENTATION AND RESULTS DISCUSSION}

The working mechanism of the current model was discussed and displayed in the following figure 7 .

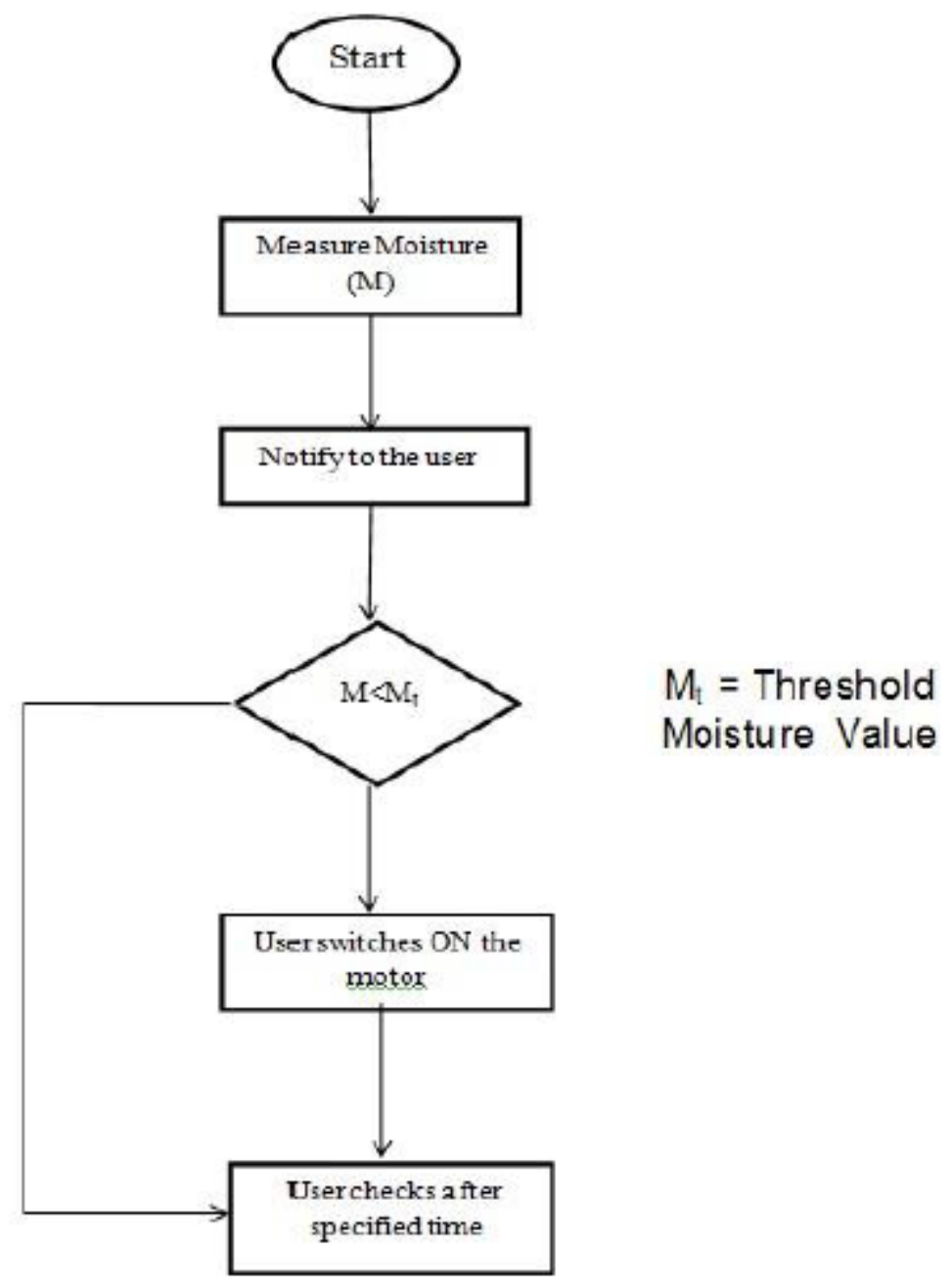

Figure 7. Working flow model of the current loT model 
At first, when the working of the current application starts, the moisture levels, temperature levels and humidity values will be verified and notified to the user or the farmer. Then the difference between the actual moisture values with the current appeared moisture values will be analyzed and based on the values the switching of the motor will be decided for further supplying of water to the units. The architecture of the total functioning of the entire unit can be observed in the below figure 8 .

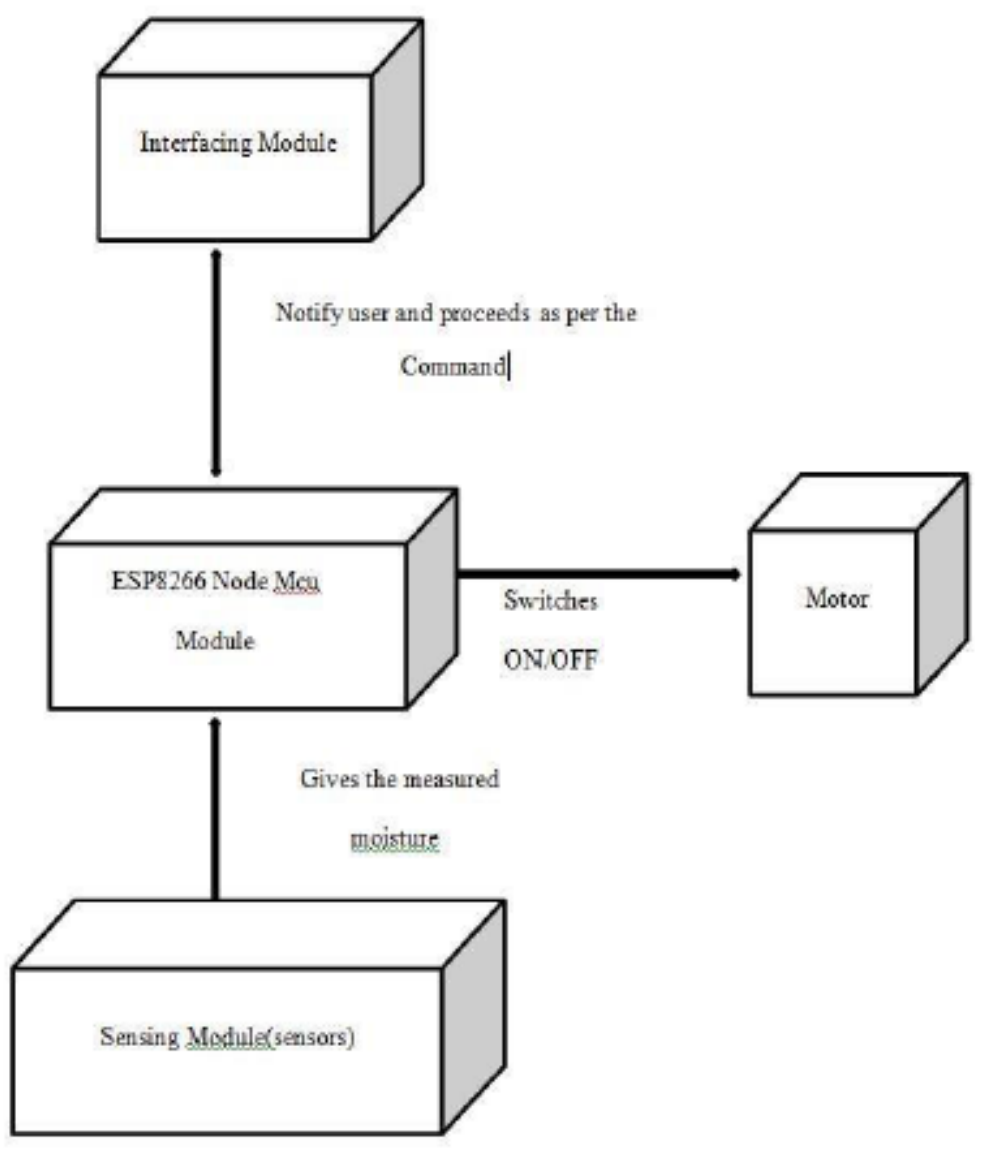

Figure 8. Architecture of the current model

Basically Blynk is a combination of platforms like IOS applications and the Android applications. This platform is mainly used to control the various devices and electronic units like the Raspberry Pi, Arduino and other devices which can be controlled by using through Internet. This current dashboard is a very simple and easy to use model that can be used for building various user interfaces and simply by drag and drop method. Blynk App Builder is used for building and developing various applications with various gadgets. The Blynk Server is also used for the communications between the various IoT units, Wi-Fi units and other devices located at various locations with the mobile devices through internet.

The home page of the Blynk software model can be seen at the following figure 9 . 


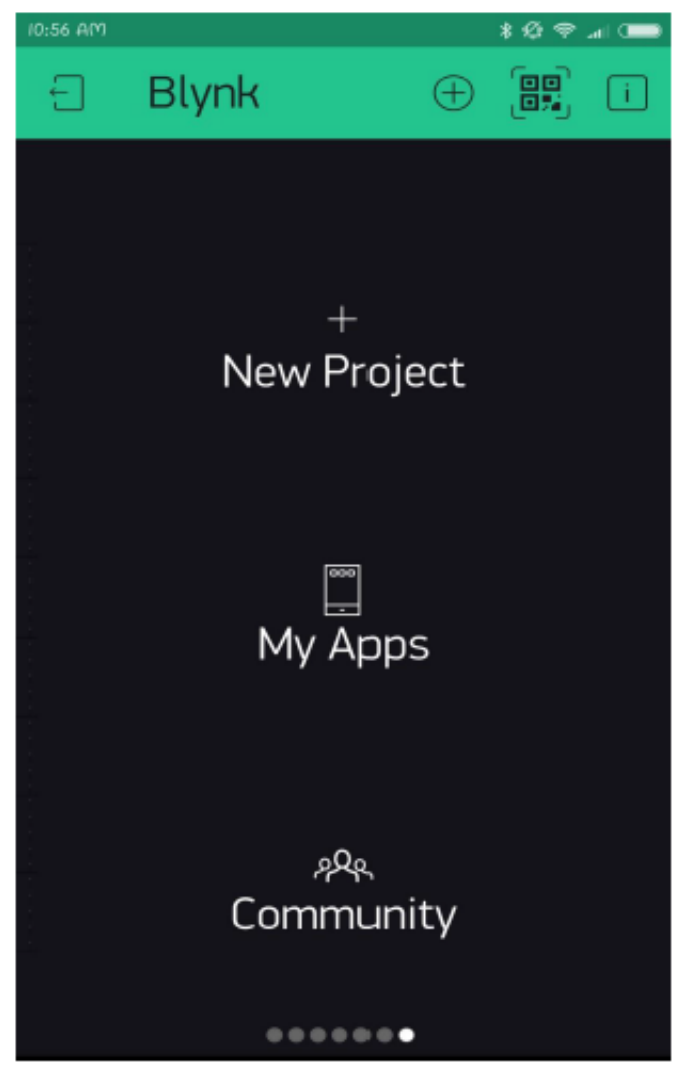

Figure 9. Home Page of Blynk Software

From the above home page of Blynk software, the users can create a new project by using three options like the creation of a new project or utilizing the existing projects or connecting with the existing users who had already developed and using for the current development of the applications. Once the software type and application is selected on the Blynk application, the hardware type of units and their requirements and other requirements will be selected based on the requirements. The connectivity selected for the current model was the Wi-Fi connectivity. The connection type was more important for the devices in the unit to work without any interruptions during the working of the current applications. 


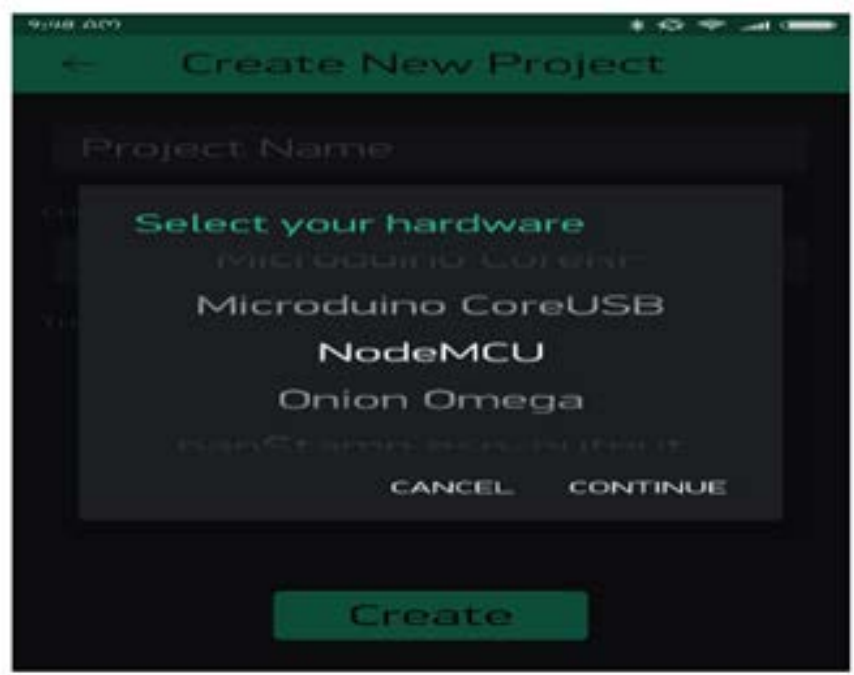

\section{Figure 10. Blynk Project Creation mode}

In the name of widgets, add various types of widgets and required things for the current project for various purposes. After adding all these operations and their tasks will be specified in the model. The mode of adding the options and their working will be decided and their modes are represented with the following figure 11.

Under MODE tab- Select whether you want this button as "push button" or "Switch". You have successfully created a GUI for Arduino as follows,
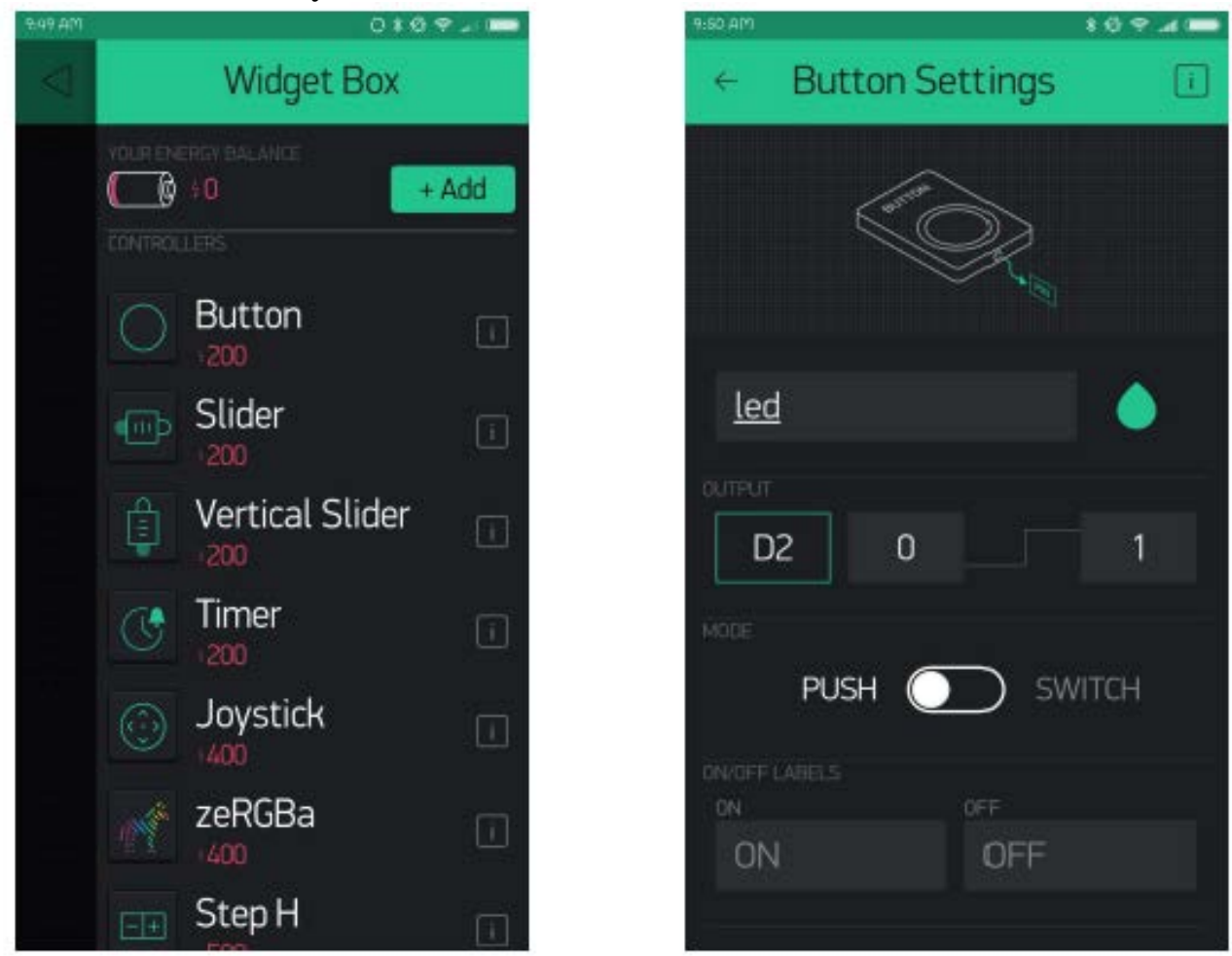

Figure 11. Widgets creation and selection of options 
Once the creation of all the applications and their tasks are decided for the current applications, the execution process of the model will be started by sending the commands and results to the other units with the mode of Wi-Fi connectivity for the mobile devices with internet connectivity.

\section{Execution}

After the app has uploaded, open the serial monitor, setting the baud rate to 9600 . Wait for the "Ready" message.

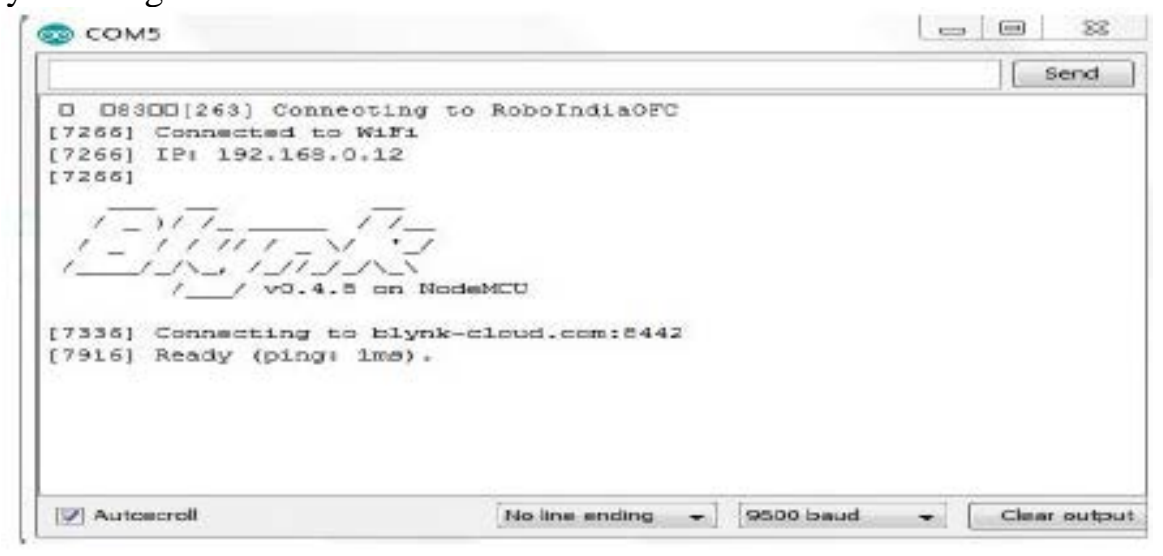

Figure 12. Execution of the current model

Then click the "Run" button in the top right corner of the Blynk app. Press the button and watch the LED. Then add more widgets to the project. They should immediately work on the ESP8266 without uploading any new firmware. Then the current model had implemented on two cases of whether the water is there or not for more number of days and also the health condition of the plants. Based on those conditions, the DC motor will be automatically switch On or Off to pump the water to the roots of the plants such that the plants can grow in a normal fashion with more energy and more healthy. 

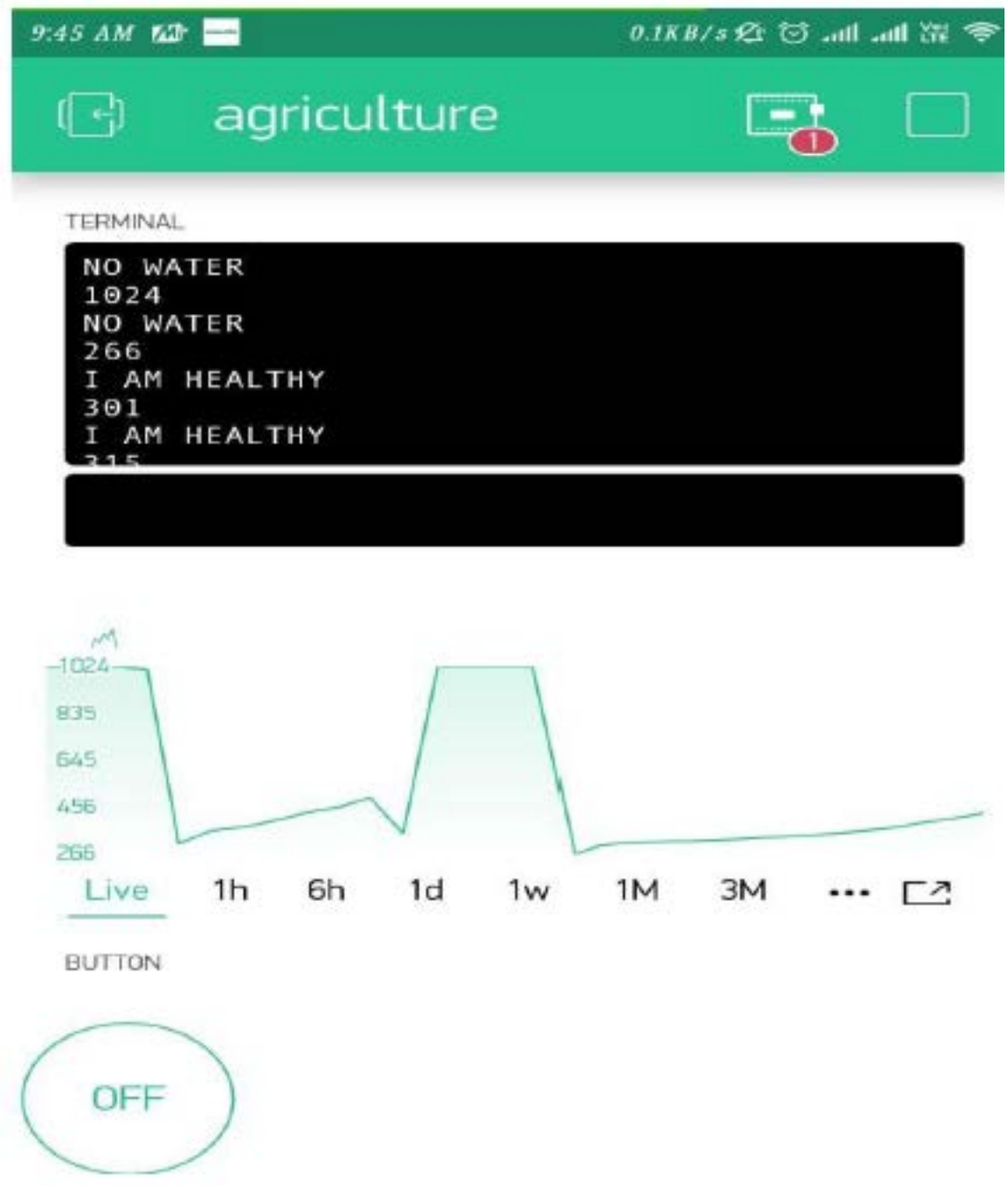

Figure 13. Output of the Model for one case 


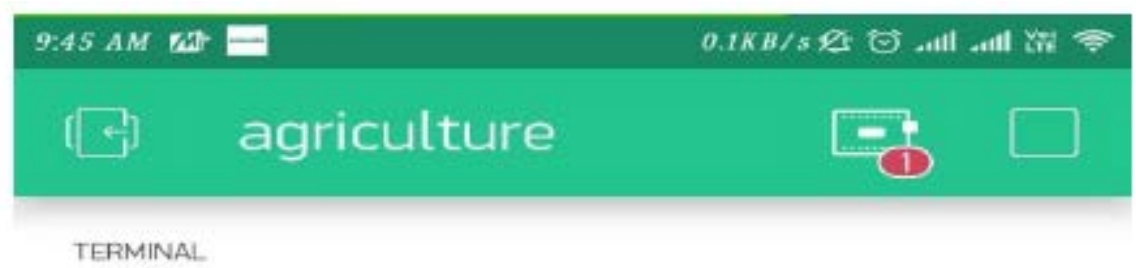

\section{NO WATER}

1024

NO WATER

266

I AM HEALTHY

301

I AM HEALTHY
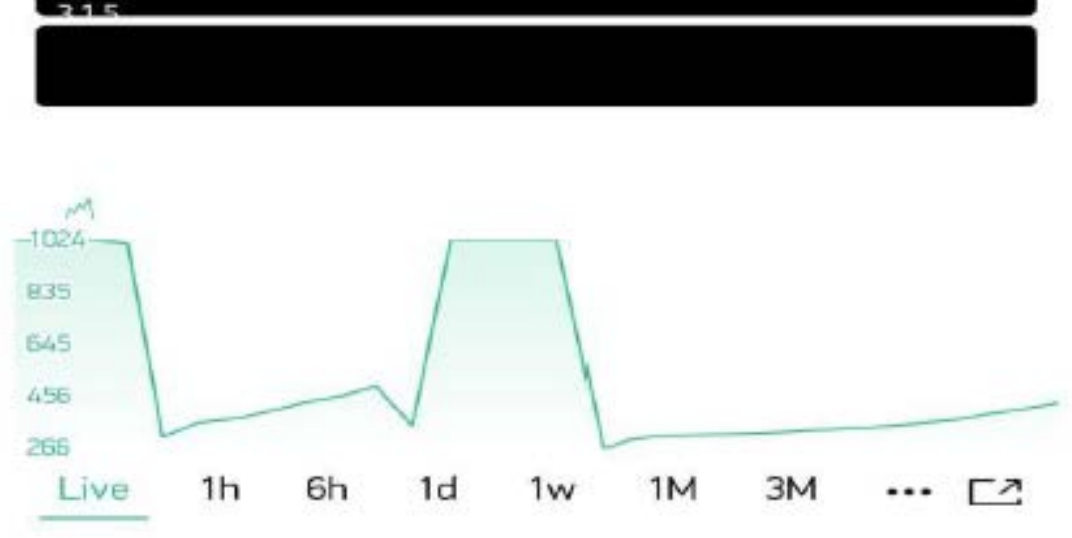

BUTTON

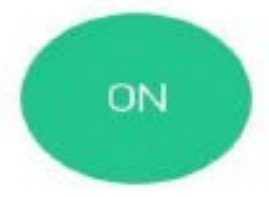

\section{Figure 14. Output of the Model for another case}

Hence, the results from the above figure gives us an idea that the proposed model was working perfectly based on the requirements of the users and the model can be further developed for incorporating more features that can help the farmers more in a less hard work with more output.

\section{CONCLUSIONS}

The utilization of Internet of Things models and units in the field of agriculture and its related areas may yield the good results and good earnings for the farmers. They can be used more and more in various agricultural industries and they will help in farming with more outputs and outcomes than the expected ones. By utilizing these techniques and models, the farmers can benefit in various features like the cost of the products, good quality, quantity increase etc. The best advantage in this application is that the farmers no need to attend for the field every time and also the farmers can control the motors and units located in the agricultural fields from anywhere in the globe simply having a connection of internet connectivity with his mobile phones. 


\section{References}

[1] Bhadane, G., Sharma, S., \& Nerkar, V. B. (2013). Early Pest Identification in Agricultural Crops using Image Processing Techniques. International Journal of Electrical, Electronics and Computer Engineering, Vol.2, No.2, pp.77-82.

[2] Saraswathi Sivamani, Saravana Kumar Venkatesan, Changsun Shin, Jangwoo Park and Yongyun Cho.Intelligent Food Control in a Livestock Environment. International Journal of Internet of Things and its Applications. Vol. 2. No. 1. Feb. (2018). GVPress. pp.1-6.

[3] Nellore Harika, Muthyala Vamsilatha, Nakka Thirupathi Rao, Debnath Bhattacharyya and Tai-hoon Kim.Performance Analysis and Implementation of Traffic Monitoring System using Wireless Sensor Network for reducing blockage in Traffic on Indian City Roads, Journal of Statistical Computing and Algorithm. Vol. 1. No. 1. Dec. (2017).GVPress. pp.15-26.

[4] Tuvakov Jemshit, Ju-Geon Pak and Kee-Hyun Park, “A Simple Energy Efficient Routing Algorithm for the IoT Environment”, International Journal of Cloud-Computing and Super-Computing. Vol. 4. No. 2. Dec. (2017).GVPress. pp.7-12.

[5] Weijie Kong. Analyzing the Usage of Data Mining in Spatial Database. International Journal of Internet of Things and its Applications. Vol. 1. No. 1. Feb. (2017).GVPress. pp.1-12.

[6] A blog written by Upasana entitled "Real World IoT Applications in Different Domains”, 22, May, 2019.

[7] Muthunoori Naresh, P Munaswamy, "Smart Agriculture System using IoT Technology”, International Journal of Recent Technology and Engineering (IJRTE), Vol.7, No.5,(2019), pp.98-102.

[8] Mohamed Rafiq, Gokul, Pradeep, Vishnu, "IoT Based Automated Irrigation System for Agriculture”, International Research Journal of Engineering and Technology (IRJET), Vol.5, No.3, (2019), pp.2307-2309.

[9] Mrs.T.Vineela, J. NagaHarini, Ch.Kiranmai, G.Harshitha, B.AdiLakshmi, "IoT Based Agriculture Monitoring and Smart Irrigation System Using Raspberry Pi”, International Research Journal of Engineering and Technology (IRJET), Vol.5, No.1, (2018), pp.1417-1420.

[10] Ho-Kyung Yang, Hyun-Jong Cha and You-Jin Song, "A Study of Secure Distributed Management of Sensing Data in IoT Environment", International Journal of Advanced Science and Technology, NADIA, Vol. 124, March (2019),pp. 21-32.

[11] Soyoung Hwang, "Monitoring and Controlling System for an IoT Based Smart Home", International Journal of Control and Automation, SERSC Australia, Vol. 10, No. 2, February (2017), pp.339-348.

[12] Joo Ho Choi, Eun-Surk Yi, Ji-Youn Kim and Byung Mun Lee, "Management of Mobility of CoAP-based IoT Device for Continuous Movement Management", International Journal of Grid and Distributed Computing, SERSC Australia, Vol.11, No.2, February (2018), pp. 55-68.

[13] Jung ho Eom, "Security Threats Recognition and Countermeasures on Smart Battlefield Environment based on IoT", International Journal of Security and Its Applications, SERSC Australia, Vol.9, No.7, July (2015), pp. 347-356.

[14] Sukhdeep Kaur, Abhinav Hans and Navdeep Singh, "An Overview to Internet of Things (IOT)", International Journal of Future Generation Communication and Networking, SERSC Australia, Vol. 9, No. 9, September (2016), pp. 239-246.

[15] N. Thirupathi Rao and Debnath Bhattacharyya, "Sensor Based Traffic Monitoring System on Indian City Roads", International Journal of Transportation, SERSC Australia, Vol.6, No.3, December (2018), pp. 1-10.

[16] Jia, Gangyong; Han, Guangjie; Rao, Huanle; Shu, Lei.: Edge Computing-Based Intelligent Manhole Cover Management System for Smart Cities, IEEE Internet of Things Journal, (2018), Vol.5, No.3, pp. 16481656.DOI: 10.1109/JIOT.2017.2786349

[17] Li, Youhuizi; Kumar, Mohit; Shi, Weisong; Wan, Jian.: Falcon: An ambient temperature aware thermal control policy for IoT gateways, Sustainable Computing-Informatics \& Systems, (2017), Vol.16, pp.48-55. 
[18] Jin Wang, Xiujian Gu, Wei Liu, Arun Kumar Sangaiah, Hye-Jin Kim, An Empower Hamilton Loop based Data Collection Algorithm with Mobile Agent for WSNs, Human-centric Computing and Information Sciences, Vol.9, No.18, Dec. 2019, pp.10-21.DOI: 10.1186/s13673-019-0179-4

[19] Jin Wang, Yu Gao , Kai Wang , Arun Kumar Sangaiah, Se-Jung Lim, An Affinity Propagation based SelfAdaptive Clustering Method for Wireless Sensor Networks, Sensors, 2019, Vol.19, No.11, 2579. DOI:10.3390/s19112579.

[20] Jin Wang, Zhongqi Zhang, Bin Li, Sungyoung Lee, and R. Simon Sherratt, An Enhanced Fall Detection System for Elderly Person Monitoring using Consumer Home Networks, IEEE Transactions on Consumer Electronics, Vol.60, No.1, Feb. (2014), pp.23-29.DOI: 10.1109/TCE.2014.6780921

[21] Jia, Gangyong; Han, Guangjie; Rao, Huanle; Shu, Lei.: Edge Computing-Based Intelligent Manhole Cover Management System for Smart Cities. IEEE Internet of Things Journal, (2018), Vol.5, No.3, pp. 16481656.DOI: 10.1109/JIOT.2017.2786349 
Ingenious Agriculture Monitoring System Using IoT And Blynk 